\title{
CONEXÕES INTERNACIONAIS: ARQUITETURAS ESTRANGEIRAS EM BRASÍLIA*
}

Sylvia Ficher

Paulo Roberto Alves dos Santos

\section{Resumo}

Poucos se lembram ou sequer se dão conta, mas graças ao status de Capital Federal, Brasília é possuidora de um excepcional acervo de arquitetura estrangeira, quase todo ele constituído por complexos diplomáticos. Localizado nos Setores de Embaixadas Sul e Norte, neles se encontram, além das representações nacionais, diversos organismos internacionais. Ampliando o interesse cultural, em suas edificações estão abrigadas significativas coleções de obras de arte, assim incorporadas ao patrimônio da cidade.

$\mathrm{Na}$ perspectiva urbana, estes dois setores findaram por ser uma grande exposição de obras de profissionais de renome, verdadeiro ponto de encontro do pensamento arquitetônico internacional, no qual predominou a expressão brutalista. A lista de edifícios e seus autores é extensa, o que explica a grande variedade de soluções adotadas, em que é sempre possível distinguir características típicas do país de origem. Mas há também diferentes graus de ênfase. Em grande parte das embaixadas prevalece a intenção de refletir a modernidade tanto de seu próprio país como a de Brasília; em algumas delas, no entanto, o objetivo é dar destaque à arquitetura tradicional e, finalmente, há aquelas em que ambas as alternativas foram harmonizadas ou convivem - bem ou mal - lado a lado.

Examinando este conjunto, começando com os exemplos de mais evidente caráter moderno, não surpreendentemente que os projetos mais significativos sejam aqueles dos países europeus e americanos. Entre os primeiros, destacam-se as embaixadas da Alemanha (1964-1971), de Hans Scharoun; da França (1972-1974), de Guillermo Jullian de la Fuente; Portugal (1972-1978), de Raul Chorão Ramalho; e da Itália (1973-1976) de Pier Luigi Nervi.

Quanto às representações latino-americanas, dentre as mais relevantes estão as embaixadas do Peru (1973-1974), de Jacques Crousse e Jorge Paez; do México (1973-1976), de Teodoro González de León, Abraham Zabludovisky e José Francisco Serrano; do Chile (1974-1977), de Juan Echenique Guzmán e José Cruz Covarrubias; do Uruguai (1978-1980), de Mario Paysse Reyes. Recentíssima foi a inauguração da embaixada argentina (1994-2011), projetada pelo Estudio MSGSSS.

Menos ligadas ao Movimento Moderno, algumas embaixadas têm como principal característica a referência à cultura tradicional dos seus países. Bons exemplos desta orientação são as embaixadas da Turquia (1977), de İlhami e Cetin Ural; da República da Coreia (1973), de Chang Sik Han; e do Marrocos (1981), de Mustafa Zeghari. Um último grupo particularmente interessante é aquele das embaixadas que buscam em sua expressão arquitetônica combinar uma estética moderna com a tradição nativa - muitas vezes resultando na convivência de edificações apresentado linguagens distintas. Este é o caso da embaixada do Japão (1970-72 e 1976), construída em duas etapas, projetadas respectivamente por Yoshimi Ohashi e Fumihiko Maki.

* Trabalho apresentado no $90 \mathrm{Se}-$ minário DOCOMOMO Brasil, Brasília, 2011. 
Presenças diferenciadas são a representação da Espanha (1972-1976), de Rafael Leoz, e o conjunto de embaixadas dos países nórdicos, todas proximamente agrupadas: Suécia (1974), de Helge Zimdal; Dinamarca (1971-1976), de Jørgen Bo; Finlândia (1974), de Jonas Cedercreutz; e Noruega (1974), de John Engh e Jon Seip.

Por fim, cabe salientar que os setores de embaixadas ainda não estão inteiramente ocupados. Muitos países ainda mantêm lotes vagos, outros estão aguardando a doação de terras. Algumas representações estão com suas obras em andamento; este é o caso da sede do Programa das Nações Unidas para o Desenvolvimento, PNUD, projetado por Gomes Machado Arquitetos Associados e Paulo Bruna Arquitetos Associados em 2004.

Palavras-chave: embaixada. representação estrangeira. arquitetura brasiliense.

\section{Abstract}

Few remember or even realize, but thanks to its status as Federal Capital, Brasilia has a major assortment of foreign architecture, almost all of it diplomatic complexes. Located in the so-called Embassies Sectors South and North, in addition to national representations, these two sectors are home to several international institutions. Expanding their cultural interests, these buildings house significant collections of works of art, thus incorporated to the city assets.

In the urban perspective, these sectors are a great international fair of works by renowned professionals, and a meeting point of world architectural thought, in which a Brutalist expression predominates. The list of buildings and their authors is extensive, which explains the variety of solutions adopted; however, it is always possible to distinguish the typical characteristics of the country of origin. But there are also different degrees of emphasis. Largely prevails these embassies intended to reflect both the modernity of their own countries and of Brasilia, but sometimes the aspiration is to highlight their traditional architecture. Lastly, there are those in which both alternatives were harmonized or packed together-well or poorly—side by side.

Examining this ensemble, starting with the most obvious examples of modern nature, not surprisingly the most significant designs are those of European and Latin American countries. Among the former, there are outstanding embassies as those of Germany (1964-1971), by Hans Scharoun; France (1972-1974), by Guillermo Julian La Fuente; Portugal (1972-1978), by Raul Chorão Ramalho; and Italy (1973-1976), by Pier Luigi Nervi.

As to the Latin-American representations, among the most relevant are the embassies of Peru (1973-1974), by Jacques Crousse and Jorge Paez; Mexico (19731976), by Teodoro González de León, Abraham Zabludovisky and José Francisco Serrano; Chile (1974-1977), by Juan Echenique Guzman and Jose Cruz Covarrubias; 
and Uruguay (1978-1980), by Mario Reyes Paysse. The Argentinean Embassy (19942011), designed by Studio MSGSSS, was recently inaugurated.

Less identified with the Modern Movement, some embassies have as main aim the reference to the traditional culture of their countries. Good examples of this approach are the embassies of Turkey (1977), by Ilhami and Cetin Ural; Republic of Korea (1973), by Chang Sik Han; and Morocco (1981), by Mustafa Zeghari. A last group is particularly interesting: that of embassies seeking in their architectural expression to combine a modern aesthetic with their native country tradition-often resulting in the coexistence of buildings presenting quite different languages. This is the case of the Embassy of Japan (1970-72 and 1976), built in two stages, designed respectively by Yoshimi Ohashi and Fumihiko Maki.

A differentiated presence is the representation of Spain (1972-1976), by Rafael Leoz, and the ensemble of the Nordic countries embassies, all closely grouped: Sweden (1974), by Helge Zimdal; Denmark (1971-1976), by Jørgen Bo; Finland (1974), by Jonas Cedercreutz; and Norway (1974), by John Engh and Jon Seip. To conclude, it should be noted that the embassy sectors are not fully occupied. Many countries still maintain vacant lots, others are waiting for a land grant. Some representations are with their works in progress, as in the case of the United Nations Program for Development headquarters (2004), by Gomes Machado Associated Architects and Paulo Bruna Associated Architects.

Key-words: embassy; foreign representation; Brutalist architecture. 
SYLVIA FICHER

Paulo Roberto Alves dos Santos
Poucos se lembram ou sequer se dão conta, mas graças ao status de Capital Federal, Brasília é possuidora de um excepcional acervo de arquitetura estrangeira, quase todo ele constituído por complexos diplomáticos. Localizado nos Setores de Embaixadas Sul e Norte, neles se encontram principalmente legações nacionais, das quais a primeira a ser concluída foi a da Iugoslávia, inaugurada já em 1965. Atual Embaixada da Sérvia e Montenegro, foi projetada por Alexander Brezovski e é representativa da estética de formas ortogonais do modernismo dos primeiros anos da cidade.

Mas lá se encontram também diversas instituições internacionais, como a Organização Pan-Americana da Saúde (1971), projetada pelo eminente arqui- teto uruguaio Román Fresnedo Siri, também autor de sua sede em Washington (1965). Ou, mais recente, o Banco Interamericano de Desenvolvimento (1994), projeto de José Galbinski constituído por dois blocos em L de esmerado detalhamento.

Aqui já vale destacar um traço curioso: a participação de arquitetos brasileiros, seja na condição de projetista principal, seja como responsável pelo detalhamento e execução da obra. Realização de grande sucesso é a discreta Embaixada dos Países Baixos (196474), projeto de Henrique Mindlin - um dos premiados no concurso para a escolha do plano piloto da nova Capital em 1957 - que se destaca pela concisão de suas linhas modernas.
Figura 1 - Embaixada da Sérvia e Montenegro, Alexander Brezovski, 1965. Foto: RNLatvian; Fonte: http://www.panoramio.com/photo/38472496

Figura 2 - Organização Pan-Americana da Saúde, Román Fresnedo Siri, 1971. Fonte: http://www.onu. org.br/organizacao-pan-americana-da-saude-completa-110-anos/

Figuras 3 e 4-Embaixada dos Países Baixos, Henrique Mindlin, 1964-74. Fotos de Edgard Cesar; Fonte: http://www.portalad.com. br/brasilia/projetos/621/embaixada-dos-paises-baixos/
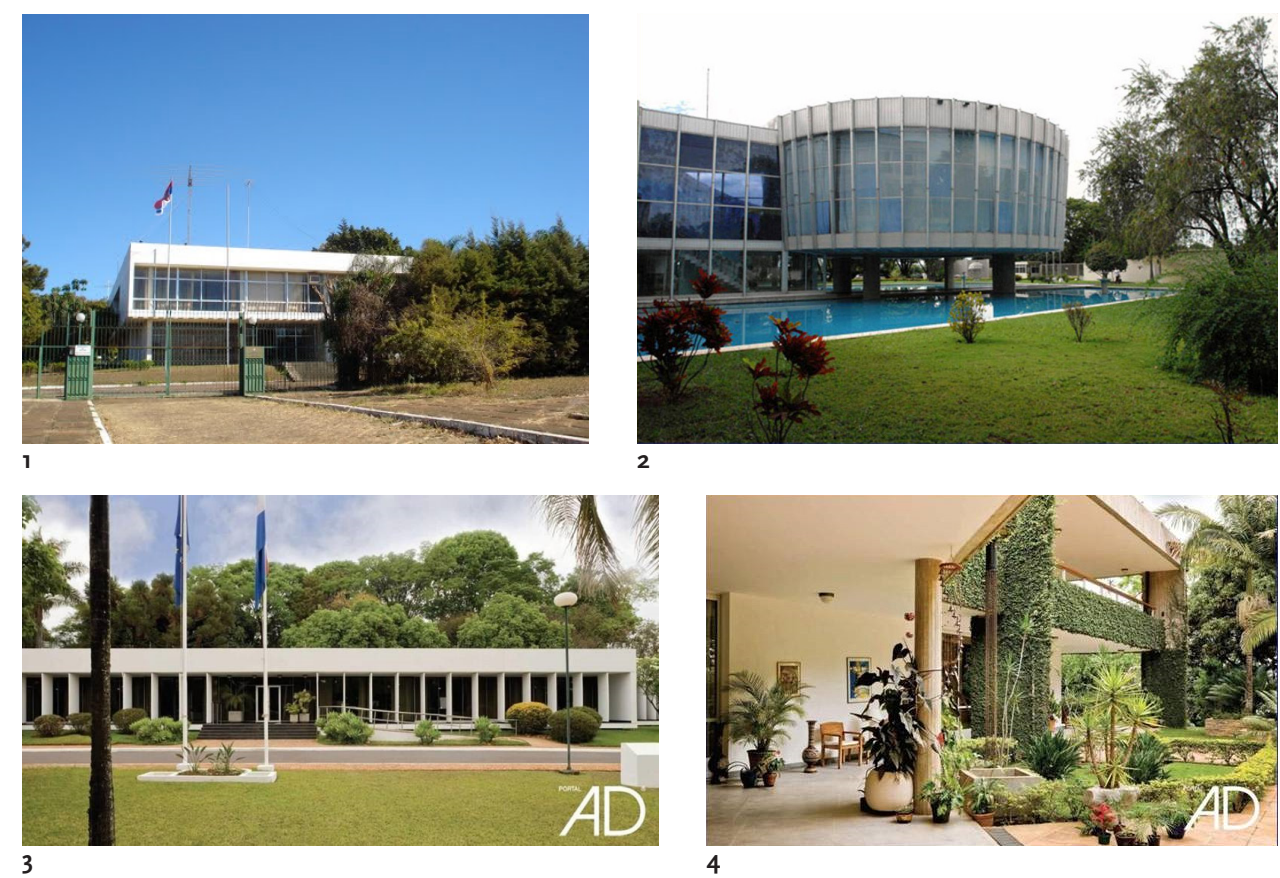
Igualmente a Embaixada da República da África do Sul (1970-74), projeto de Ítalo Campofiorito; a Embaixada do Líbano (1973), de Miguel Badra Jr; e a Embaixada do Senegal (1974-77), de Wilson Reis Netto. (Figura 5 e 6)

Contando com a colaboração de brasileiros pode-se citar a Embaixada da Bélgica (1970-74), de Nikolas Fikoff e Paulo Antunes Ribeiro; a Embaixada da Polônia (1971-73), de Andrzej Dzierzawki, Zbigniew Pawelski e Halina Swiergocka-Kaim, com Elvin Mackay Dubugras; e a Embaixada do Egito
(1975-78), de Taher Said-Fadl, Gladson da Rocha, Paulo Magalhães e Durmar Martins.

Na perspectiva urbana, estes dois setores findaram por se tornar uma grande exposição de obras de profissionais de renome, verdadeiro ponto de encontro do pensamento arquitetônico internacional. A lista de edifícios e seus autores é extensa, o que explica a grande variedade de soluções adotadas - ainda que predomine a expressão brutalista -, em que é sempre possível distinguir traços típicos do país de origem. Mas há

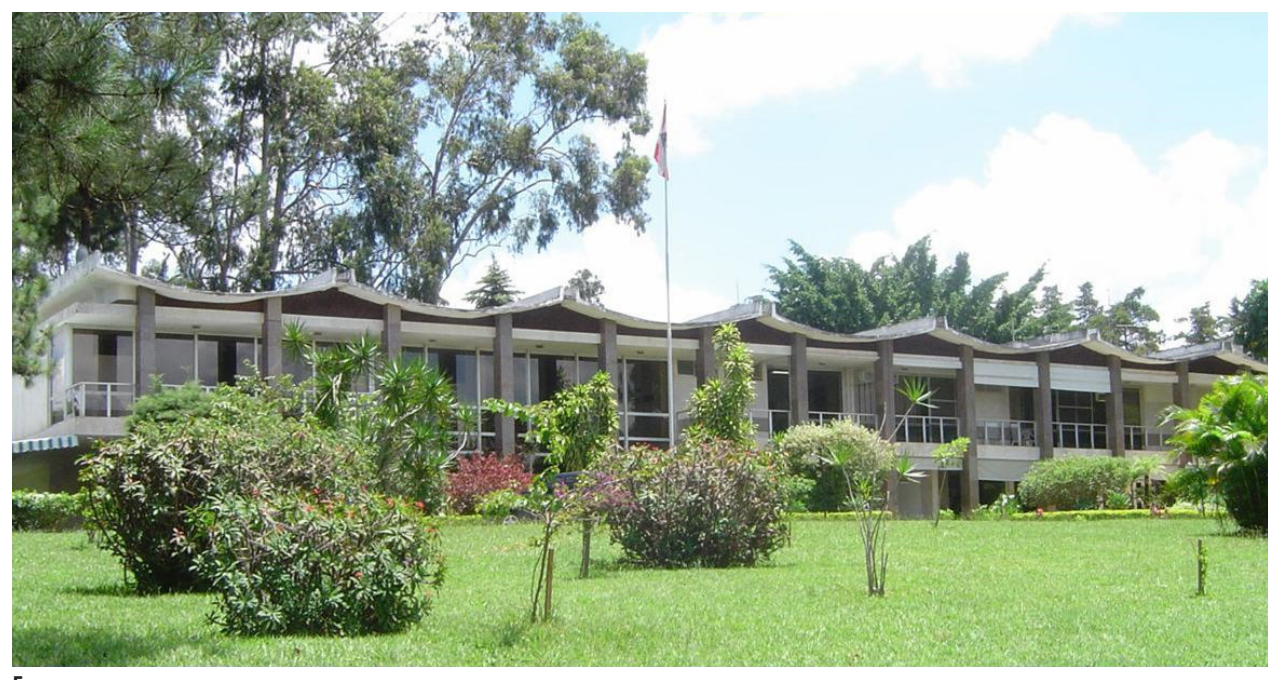

5
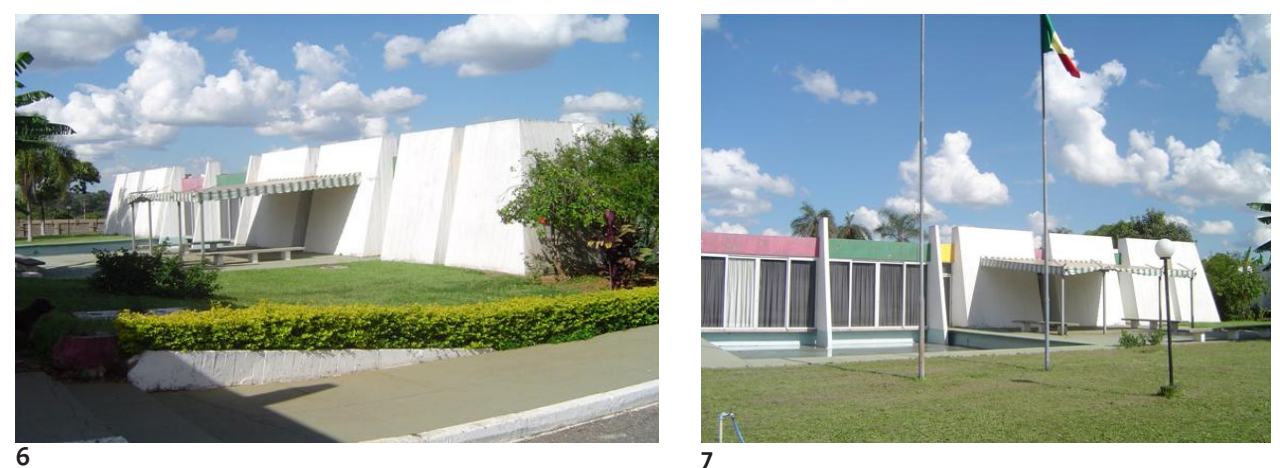

Figura 5 - Embaixada do Líbano (1973), Miguel Badra Jr. Fonte: Paulo Roberto Alves dos Santos, 2005.

Figuras 6 e 7 - Embaixada do Senegal, Wilson Reis Netto, 1973. Fonte: Paulo Roberto Alves dos Santos, 2005 . 
Figura 8 - Embaixada do Egito, Taher Said-Fadl, Gladson da Rocha, Paulo Magalhães e Durmar Martins, 1975-78. Fonte: http:// www.opengate.com.br/embegito/.

Figura 9 - Embaixada da República Tcheca, Karel Filsak, Karel Bubeníček, Jan Šrámek e Jiŕí Louda, 1963-65.http://www. mzv.cz/jnp/cz/o_ministerstvu/ budovy_architektura/nase_budovy_v_zahranici/brazilie_prvni_ projekt_velvyslanectvi_z.html.

Figura 10 - Embaixada da Eslováquia, 1973-76. Foto: RNLatvian. Fonte: http://www.panoramio. com/photo/38404635.

Figura 11 e 12 - Residência oficial, Embaixada da Alemanha, Hans Scharoun,1969. Fonte: Bundesamt für Baumwesen und Raumordnung.
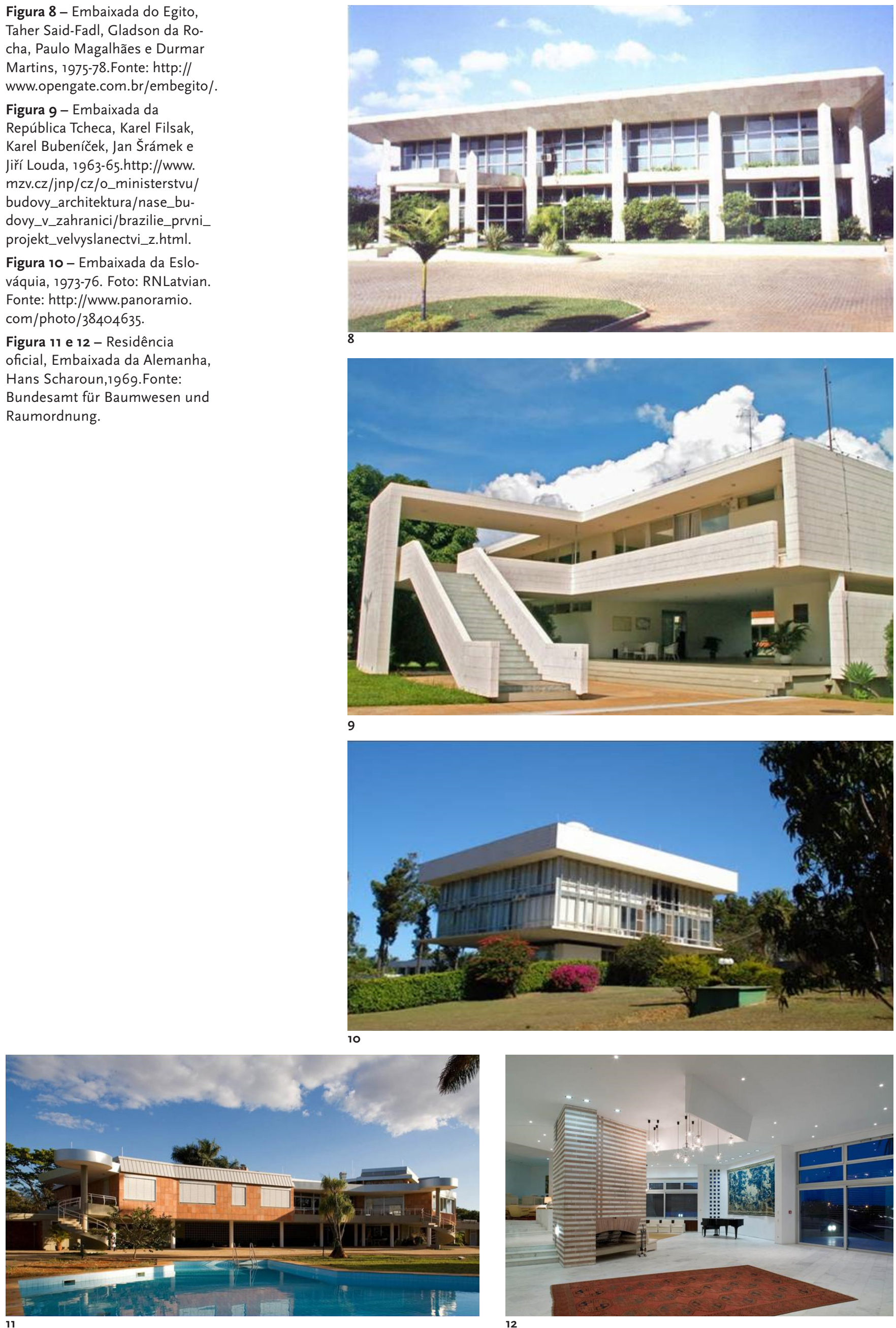
também diferentes graus de ênfase. Em boa parte das embaixadas prevalece a intenção de refletir a modernidade tanto de seu próprio país como a de Brasília; em algumas delas, no entanto, o objetivo é dar destaque à arquitetura tradicional e, finalmente, há aquelas em que ambas as alternativas foram harmonizadas ou convivem - bem ou mal - lado a lado. Ampliando o interesse cultural, nessas edificações estão abrigadas significativas coleções de obras de arte, assim incorporadas ao patrimônio da cidade.

Porém não é só arquitetura que nelas se lê; há também circunstâncias políticas aqui registradas. Veja-se o caso da antiga Embaixada da Tchecoslováquia: suas instalações foram construídas em duas etapas: inicialmente a chancelaria e a residência para o corpo diplomático (196365), projetadas pelos arquitetos Karel Filsak, Karel Bubeníček, Jan Šrámek e Jiří Louda, e por fim a residência do embaixador, com pequeno auditório (197376), cujo autor não foi identificado. Com o desmonte dos governos comunistas do leste europeu em fins da década de 1980 e consequente divisão do país em 1993, o conjunto foi redistribuído, ficando a Embaixada da República Tcheca instalada, desde então, na edificação destinada à residência do corpo diplomático. Para a Embaixada da Eslováquia ficaram a chancelaria e a residência do embaixador.

Examinando este conjunto, começando com os exemplares de mais evidente feição moderna, não surpreendentemente aquelas de países europeus e americanos.

Entre os primeiros, uma obra excepcional é a Embaixada da Alemanha (1964-71), projeto de um dos grandes mestres da arquitetura moderna, Hans Scharoun. Este é o seu único trabalho fora da Alemanha e foi concebido precisamente à época de duas de suas realizações mais elogiadas - a sede da Orquestra Filarmônica (1956-1963) e um dos prédios da Biblioteca Nacional (1964-1978), ambos em Berlim. A embaixada é constituída pelo departamento de assuntos estrangeiros, a residência oficial e várias casas para o corpo diplomático, e demonstra à perfeição a arquitetura exuberante e pouco ortodoxa de seu autor, ressaltada pelos jardins de Roberto Burle Marx. Como reconhecimento de suas qualidades, integra o patrimônio histórico e artístico alemão.

A Embaixada da França (1972-74) tem uma história curiosa - detalhadamente contada no livro Embaixada da França (2009), organizado por Colette di Matteo e Jean-Martin Tidor -, em que mais uma vez Le Corbusier perdeu a oportunidade de ter uma obra sua em solo brasileiro. $\mathrm{O}$ estudo preliminar que apresentou em 1963, famoso pela inclusão de um edifício com oito andares, findou por ter seu desenvolvimento adiado por toda ordem de razões. Com o falecimento do mestre franco-suíço em 1965, seu associado, o chileno Guillermo Jullian de la Fuente, foi convidado para dar continuidade à tarefa. Devido a sérias 

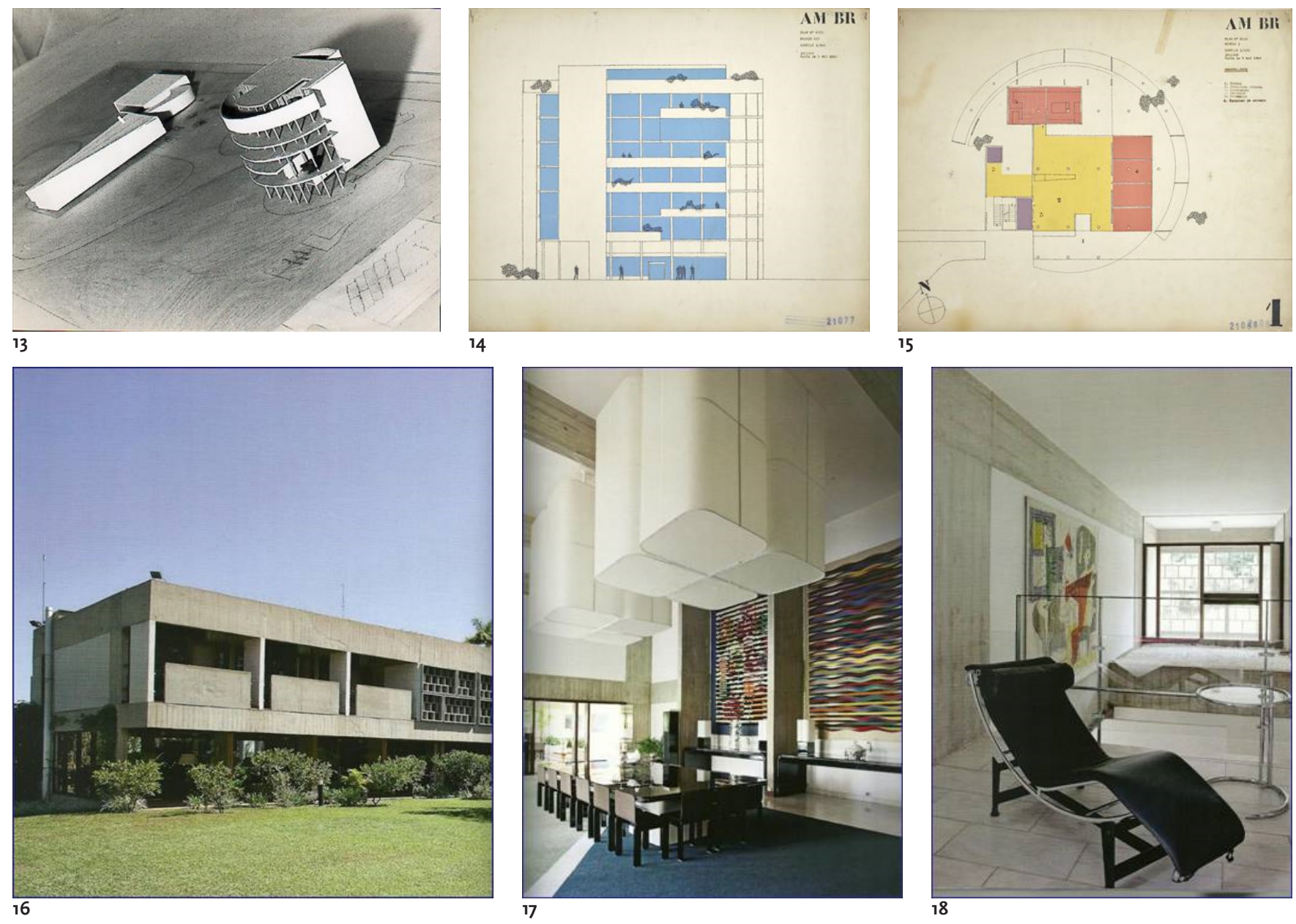

15
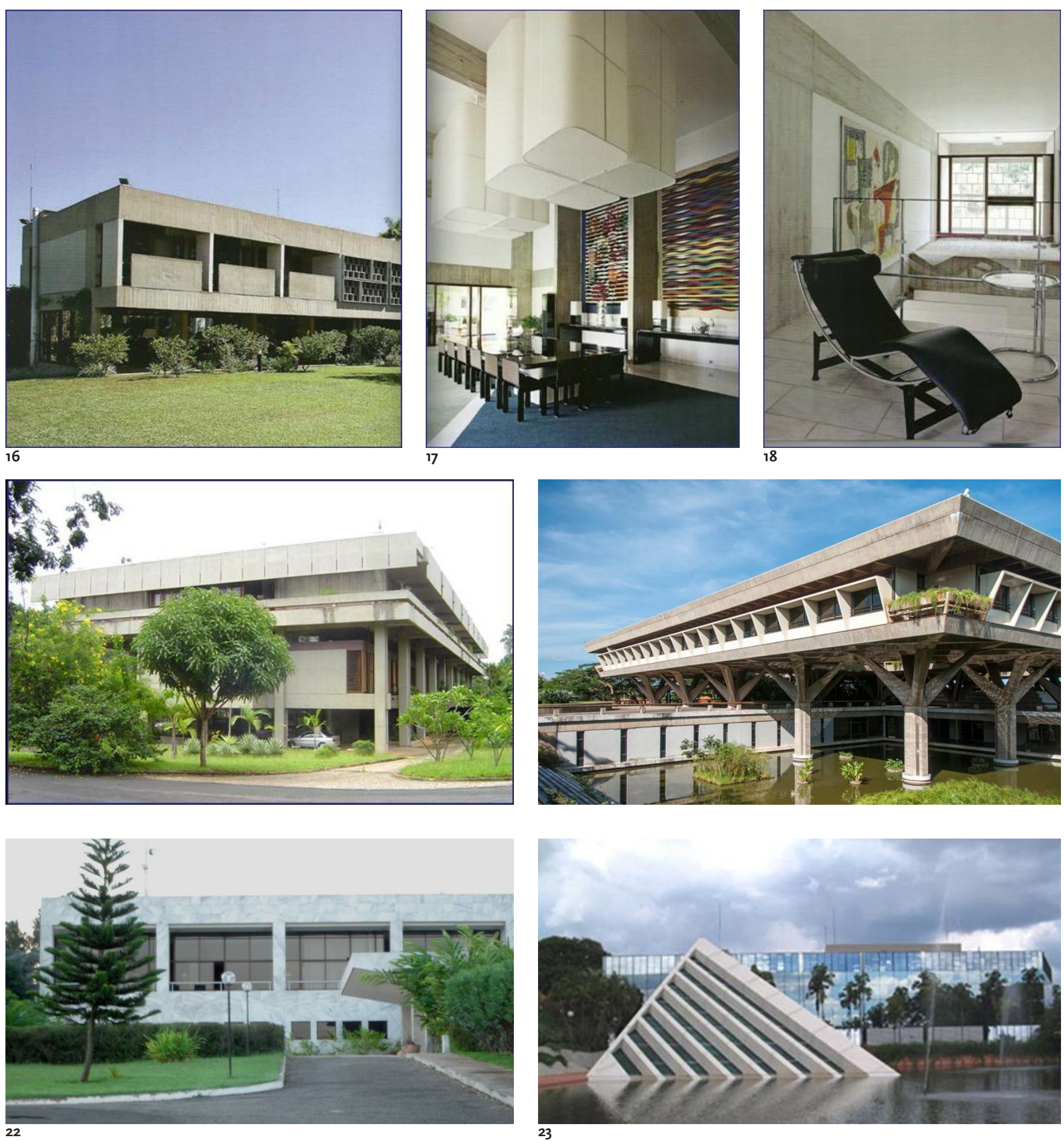


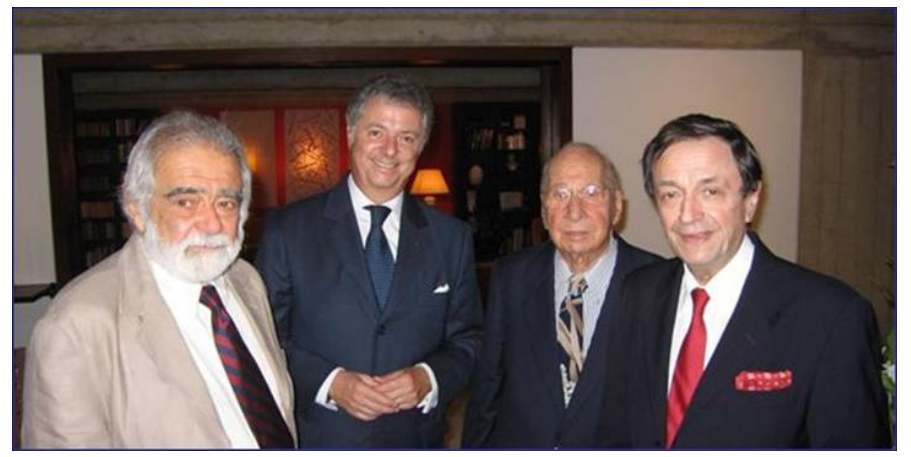

Figura 19 - Guillermo Jullian de la Fuente, Embaixador Antoine Pouillieute, Ernesto Silva e Martin Boyer na Embaixada da França, 2007. Fonte: Sylvia Ficher.

mudanças no programa, este elaborou um novo projeto, de grande beleza, constituído por diversos blocos, todos articulados entre si e com seus espaços interiores requintadamente decorados por Michel Boyer e integrados aos jardins. Seja como for, a presença de Le Corbusier foi garantida pela incisiva adoção de uma estética brutalista e pela presença de uma de suas tapeçarias, Bogotá, ornando a residência do embaixador. Em 2007, o conjunto passou por uma renovação feita sob a supervisão de seus autores, ocasião em que visitaram a obra.

Por compreensíveis razões históricas, a Embaixada de Portugal (1972-1978) é aquela mais próxima do Eixo Monumental, concebida por Raul Chorão Ramalho. Impecável exemplar da arquitetura brutalista da década de setenta, contida em um único volume regular elevado sobre pilares e protegido por abas verticais de concreto aparente nas fachadas do piso superior, o edifício se integra por todos os lados a generosos jardins.

Até mesmo o arrojado Estúdio Nervi deixou a sua marca em Brasília, graças à Embaixada da Itália (1973-1976). Como seria de esperar, a solução adotada pelo próprio Pier Luigi Nervi é fortemente determinada pela concepção estrutural. $\mathrm{O}$ edifício é organizado em um único bloco de grandes proporções, elevado sobre uma série de robustos pilares, cada um deles abrindo-se em quatro ramos, e recobrindo parcialmente um extenso espelho d'água e amplos jardins internos, projetados pelo paisagista Ney Ururahy Dutra. Em um gesto de ami- zade, a embaixada abriga quatro grandes pinturas de Candido Portinari.

Mesmo que de modestas dimensões, a discreta Embaixada da Suíça (1977), projetada pela equipe de Hans e Annemarie Hubacher, é típica da arquitetura brutalista dos anos setenta, acrescida de excepcional qualidade de construção e acabamentos. Se Nervi, por que não George Candilis? Em seu projeto para a Embaixada da Grécia (1980) - desenvolvido por José Galbinski -, a chancelaria, o consulado e a residência do embaixador foram abrigados em um único volume de linhas ortogonais, interligados por amplas passarelas, pátios internos e jardins suspensos. O revestimento dominante é o mármore branco.

Um dos poucos exemplos de pós-modernismo em Brasília, a Embaixada da Grã-Bretanha (1978-83), projetada por Alfred Coutts, é constituída por inúmeras edificações, articuladas por jardins também do paisagista Ney Ururahy Dutra. Dentre elas, destaca-se o auditório - uma pirâmide pousada em um espelho d'água, que se reflete no pano de vidro da fachada da chancelaria.

$*$

Quanto às representações americanas, nelas predomina indiscutivelmente a expressão brutalista. Devido à sua estrutura, formado por pilastras e lâminas inclinadas de concreto armado, a Embaixada do Peru (1973-1974), de Jacques Crousse e Jorge Paez, possui uma intrigante volumetria.
Figuras 13, 14 e 15 - Estudo preliminar para a Embaixada da França, Chancelaria, Le Corbusier, 1963. http://www.fondationlecorbusier.fr/corbuweb/ morpheus.aspx? sys Id=13\&lrisObjectld $=5578 \&$ sys Language $=-$ $\mathrm{fr}$-fr\&itemPos $=1 \&$ item Sort=fr-fr sort_string $1 \&$ item $C o u n t=5 \&$ sys $P a-$ rentName $=$ Home\&sysParentld $=11$

Figuras 16, 17 e 18 - Embaixada da França, Guillermo Jullian de la Fuente, interiores de Marcel Boyer, 1972-74. Fotos: Tuca Reinés; Fonte: Colette di Matteo e Jean-Martin Tidor, 2009.

Figura 20 - Embaixada de Portugal, Raul Chorão Ramalho, 1972-78. Fonte: Paulo Roberto Alves dos Santos, 2005.

Figura 21 - Embaixada da Itália, Estúdio Nervi, 1973-76.Fotos: Joana França, 2011.

Figura 22 - Embaixada da Grécia, George Candilis, 1980. Fonte: Paulo Roberto Alves dos Santos, 2005.

Figura 23 - Embaixada do Reino Unido, Alfred Coutts, 1978-83. Fonte: http://www. skyscrapercity.com/showthread. php? $=90612206$. 


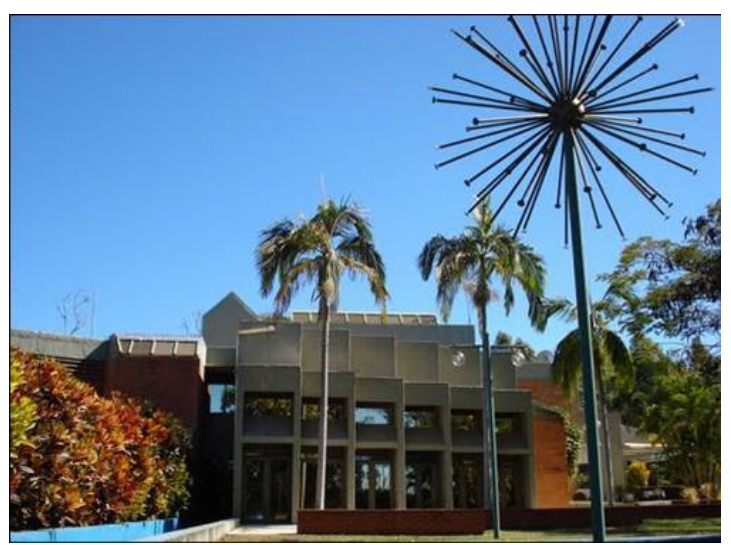

24

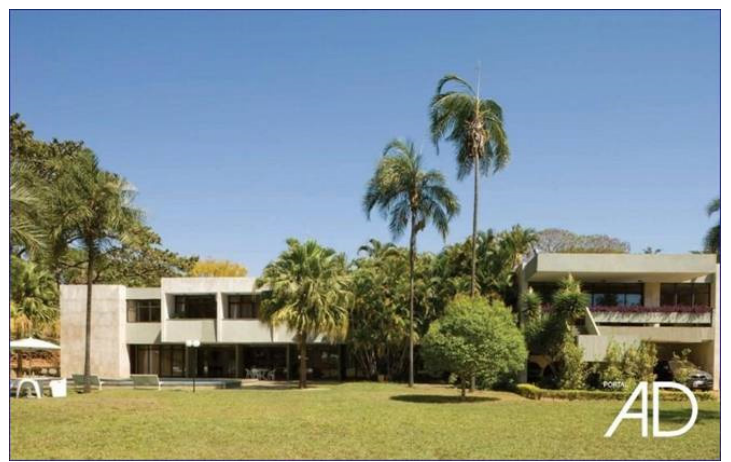

25
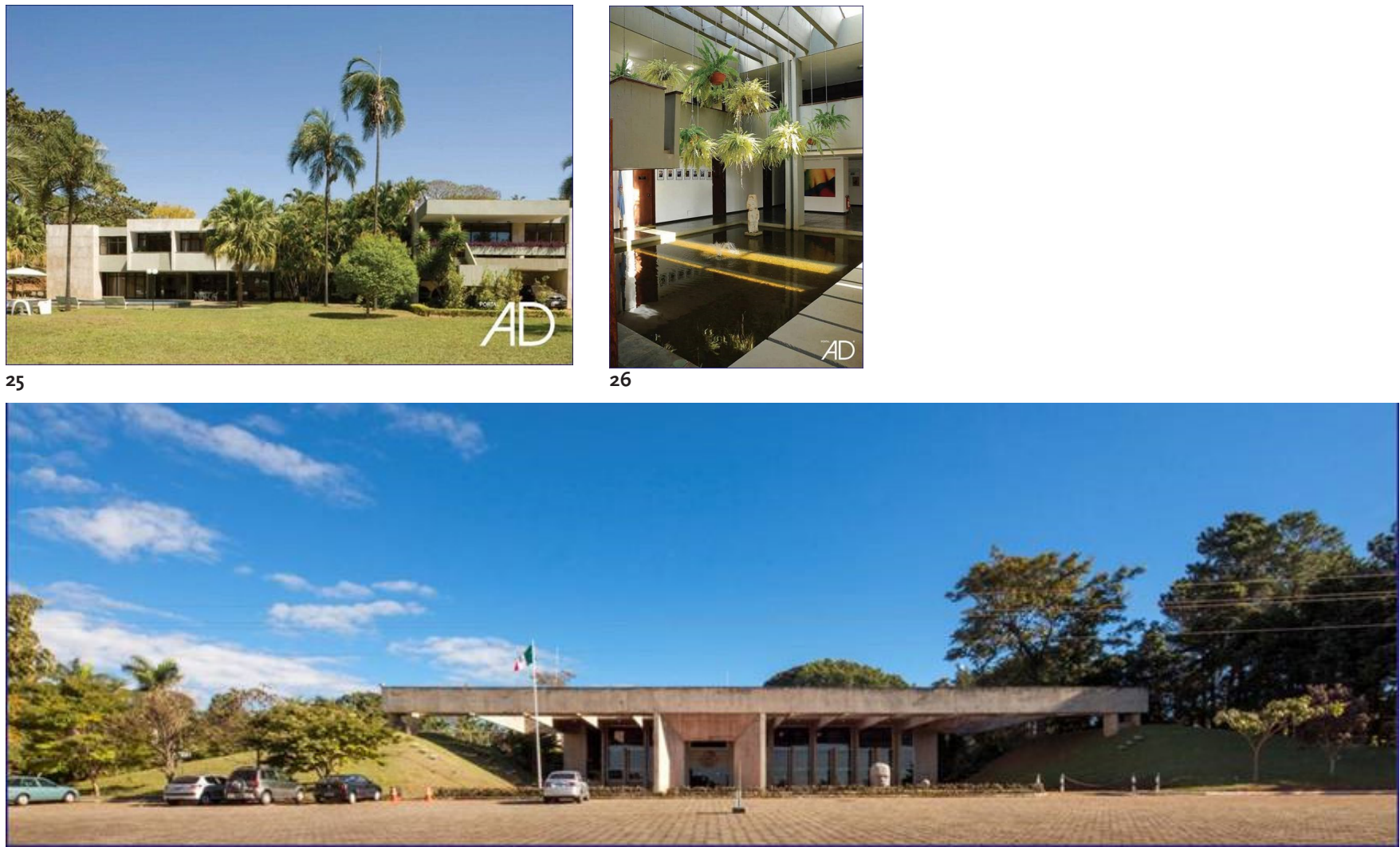

27

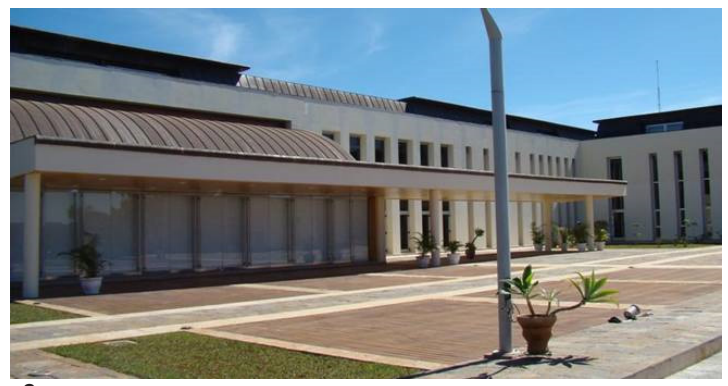

28

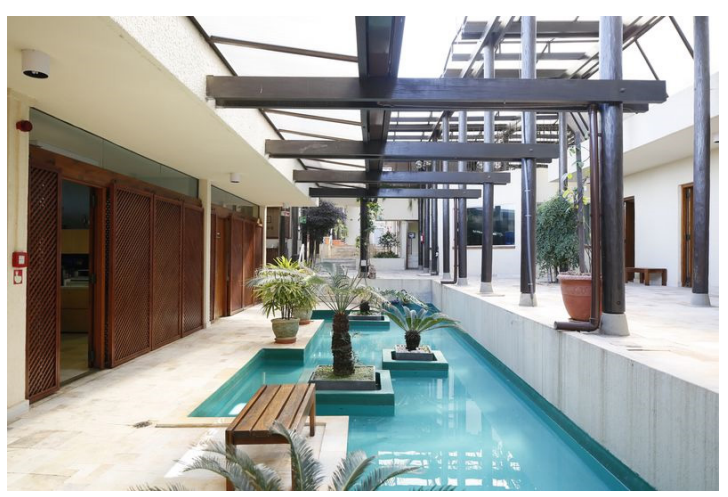

Figura 24 - Embaixada do Peru, Jacques Crousse e Jorge Paez, 1973-1974. Foto: RNLatvian; Fonte: http://www.panoramio.com/photo $/ 38405660$.

Figuras 25 e 26 - Embaixada da Colômbia, Cesar Barney, 1979-81. Fotos: Edgard Cesar; Fonte: http://www.portalad.com.br/brasilia/projetos/607/ embaixada-da-colombia/

Figura 27 - Embaixada do México,

Teodoro G. de León, Abraham Zabludovski e J. F. Serrano, 1974. Fotos: Joana França, 2011.

Figura 28 - Embaixada da Argentina, Estudio MSGSSS, 1994-2011. Fonte: http://brasilterraquerida.bligoo.com/ content/view/5213151/Cristina-Kirchner-inaugurou-Embaixada-Argentina-no-Brasil.html

Figura 29 - Embaixada do Canadá, Thompson, Berwick, Pratt \& Partners, 1970-78. Foto: Joana França, 2013. 
A Embaixada do Chile (19741977), dos destacados arquitetos Juan Echenique Guzmán e Jose Cruz Covarrubias - autores do projeto da embaixada chilena na Argentina (1966-69) - está organizada em dois blocos independentes, cujas áreas internas se desenvolvem em torno de amplos jardins de inverno. Uma curiosidade é a cobertura revestida por chapas de cobre, uma das maiores riquezas do país. A arquitetura elegante da Embaixada do Uruguai (1978-1980), uma excelente representante das obras de seu autor, Mario Paysse Reyes, é outro exemplo do uso extensivo de concreto aparente. Projetada por Cesar Barney, arquiteto colombiano então há muito radicado em Brasília, a sóbria Embaixada da Colômbia (1979-81) é constituída pelos dois blocos da chancelaria e, separada por espelho d'água, pela residência do embaixador, também predominando o emprego do concreto aparente.

Indiscutivelmente, a Embaixada do México (1973-1976), de Teodoro González de León, Abraham Zabludovisky e José Francisco Serrano, é uma das mais imponentes do setor. O complexo é composto por chancelaria, residência oficial e oito casas geminadas, e está posicionado de tal modo que os elementos da paisagem escondem parcialmente todas as edificações. Isso se aplica em especial à chancelaria, concebida de modo a ter suas fachadas laterais ocultas por altos taludes gramados, nos quais se apóiam grandes vigas de concreto armado protendido, dando forma a um monumental pórtico de acesso. No seu saguão pode ser vista uma excelente coleção de
De nota, esta é a única embaixada que, deixando de lado questões de segurança, está aberta para o espaço público à sua frente.

Recentemente inaugurada, a Embaixada da Argentina (1994-2011), projetada pelo Estudio MSGSSS, dos arquitetos Flora Manteolo, Javier Sánchez Gómez, Josefa Santos, Justo Solsona e Carlos Sallaberry, é representativa de tendências internacionais mais adequadamente rotuladas de neobrutalismo.

Exceção neste conjunto, diferencia-se a Embaixada do Canadá (1970-78), projeto de Thompson, Berwick, Pratt and Partners, pelo caráter moderno, porém não brutalista. Nela foi enfatizada uma composição dinâmica de volumes ortogonais, conectados por caminhos abrigados sob pérgulas de madeira e vidro. A evidente preocupação com o controle das condições ambientais resultou no emprego de treliças de madeira que integram jardins internos e espelhos d'água aos ambientes de suas diversas dependências. Novamente, destaca-se o paisagismo de Ney Ururahy Dutra.

Ainda que menos vinculadas ao Movimento Moderno, mas não menos de sabor brutalista, algumas representações têm como principal característica referências à cultura tradicional do seu país. Essa intenção está claramente plasmada na Embaixada da Turquia (1977). 
Figura 30 - Embaixada da Turquia,

Ílhami e Cetin Ural, 1977. Foto: Joana

França, 2011.

Figura 31 - Embaixada da Coréia,

Chang Sik Han, 1973. Foto: Joana

França, 2011.

Figuras 32 e 33 - Embaixada do Marrocos, Mustafá Zeghari,1981-92. http:// www.anualdesign.com.br/brasilia/projetos/620/embaixada-do-marrocos/

Figura 34 - Embaixada do Japão,

Fumihiko Maki, 1976. Foto: RNLatvian;

http://www.panoramio.com/pho-

to/38450911

Figura 35 - Embaixada da Espanha,

Rafael Leóz, 1972-76. Foto: Joana

França, 2011.

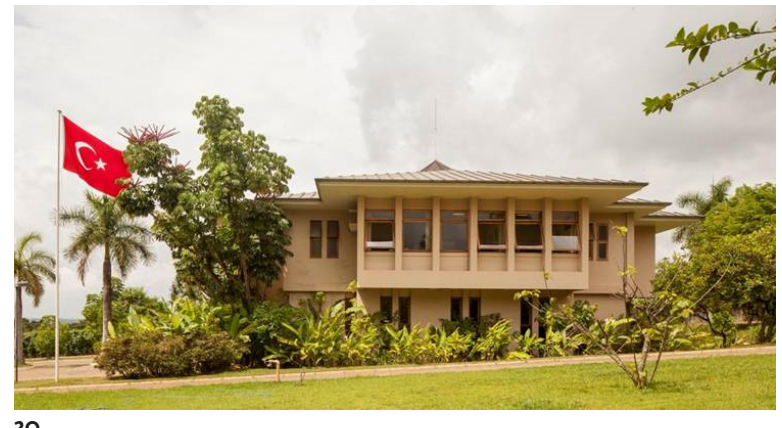

30
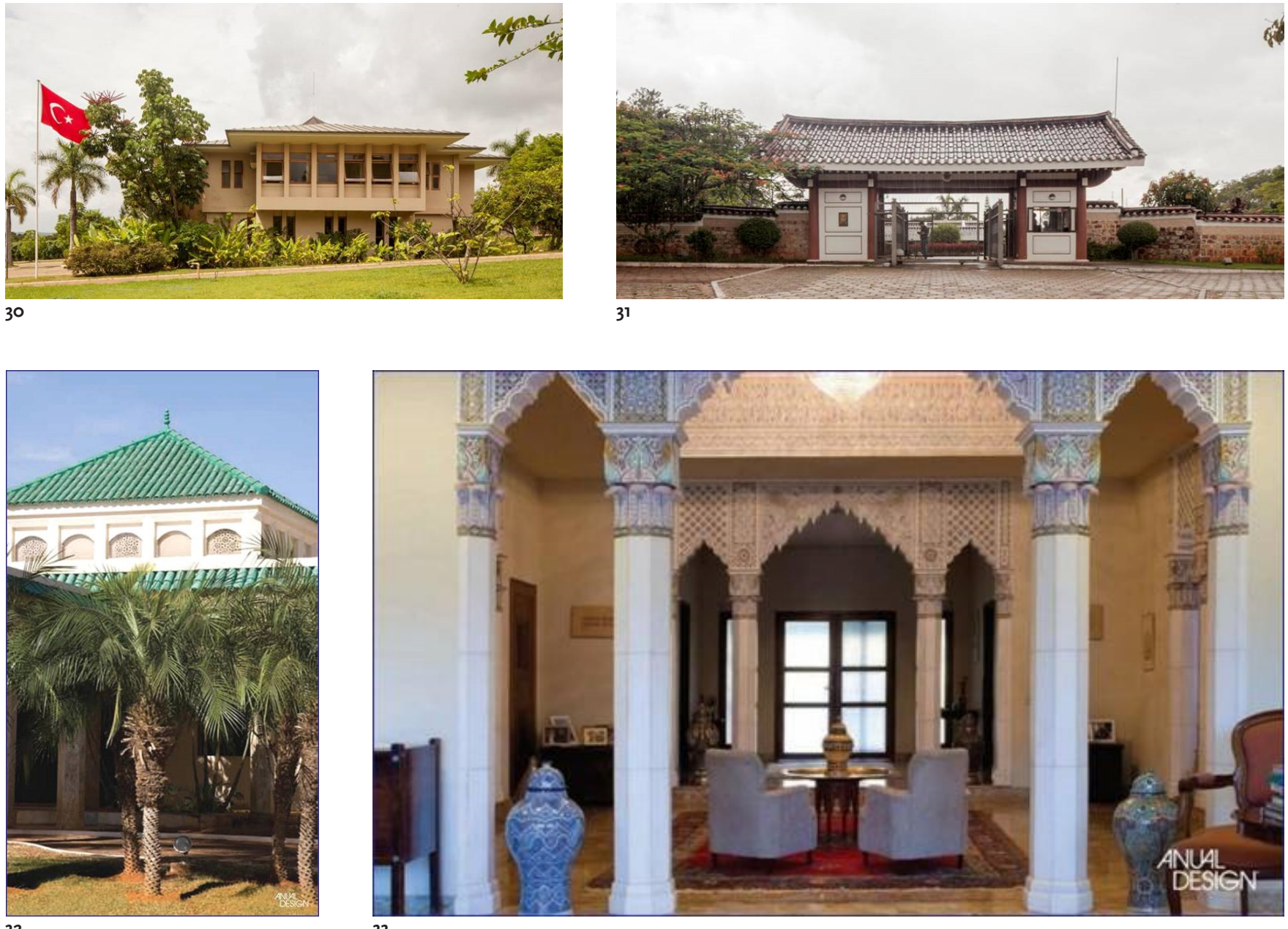

32
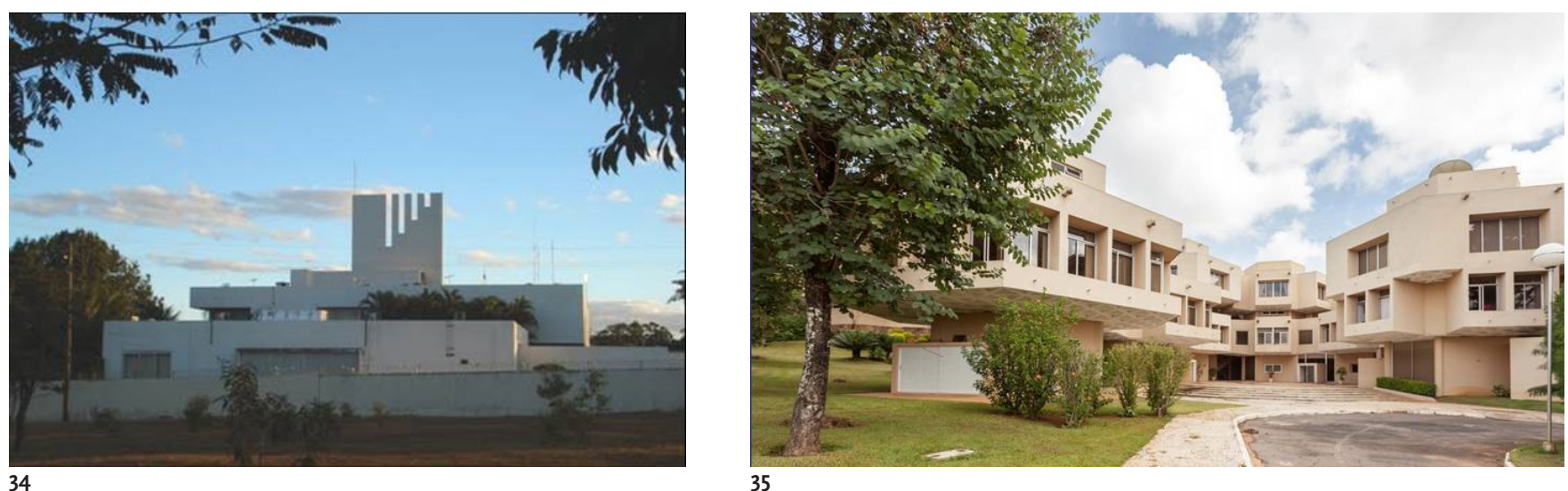
O projeto, de İlhami e Cetin Ural, foi escolhido em um concurso público, cujo edital expressamente recomendava o uso de traços típicos da arquitetura vernácula.

A Embaixada da República da Coreia (1973), projetada por Chang Sik Han, é outro exemplar de arquitetura nativista, opção indicada especialmente em seu imponente portão de entrada.

Do mesmo modo, a Embaixada de Marrocos (1981-92), de Mustafa Zeghari, traz em suas formas, materiais e cores, uma evidente referência à cultura do noroeste da África. Constituído por chancelaria, residência do embaixador e três residências para funcionários, o complexo exibe uma riqueza de detalhamento, uma qualidade de materiais e um requinte de mão-de-obra incomuns na cidade.

Um último grupo particularmente interessante é aquele das representações que buscam em sua expressão arquitetônica combinar uma estética moderna com a tradição nativa de seu país - muitas vezes fazendo conviver edifícios concebidos em linguagens muito distintas. Este é o caso da Embaixada do Japão. De 1970 a 1972 foram construídos os seus escritórios, abrigados em um pavilhão de forte caráter vernáculo, projetado por Yoshimi Ohashi. Em 1976, o conjunto foi acrescido da chancelaria e da residência do embaixador, ambos em linhas modernas, projetado pelo prolífico arquiteto Fumihiko Maki, detentor do Prêmio Pritzker de 1993.

Projetada por David Resnik, arquiteto brasileiro que se radicou na Palestina em
1947, a Embaixada de Israel (1974-75) arquitetura moderna e vernácula, na linha do regionalismo crítico. A Embaixada da Espanha (1972-1976) é um dos edifícios mais distintivos do setor, e ápice das pesquisas desenvolvidas por seu autor, o aclamado arquiteto Rafael Leoz. Composta pelo agrupamento de módulos de planta hexagonal semelhante, mas de diferentes alturas, apesar de sua evidente expressão modernista, a sua organização espacial, em particular os pátios internos com fontes revestidas por azulejos decorados em estilo mourisco, traz à memória a arquitetura tradicional espanhola.

Uma presença excepcional é aquela dos países nórdicos, cujas representações estão agrupadas em uma mesma quadra. Elas são a Embaixada da Suécia (1974), de Helge Zimdal; a Embaixada da Dinamarca (1971-1976), de Jørgen Bo; a Embaixada da Finlândia (1974), de Jonas Cedercreutz - onde se pode apreciar um mural de Alvar Aalto -; e a Embaixada da Noruega (1974), de John Engh e Jon Seip. Todas elas seguem um mesmo padrão: estão organizadas em várias edificações, sempre empregando uma única solução construtiva e uma mesma linguagem arquitetônica, diferindo apenas em suas dimensões. Outra característica comum é o cuidado paisagismo.

Finalmente, deve-se salientar que os setores de embaixadas ainda não foram integralmente ocupados. Muitos países instalaram-se em diferentes bairros da 


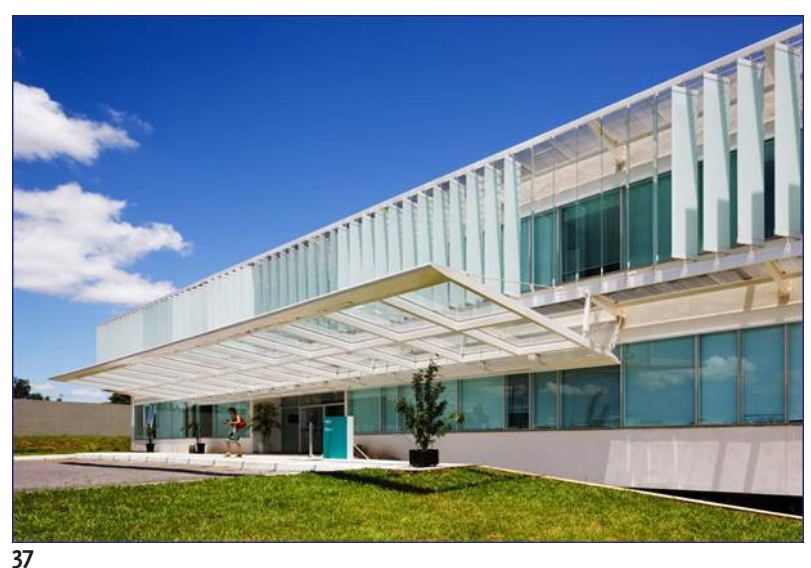

Figura 36 - Embaixada da Dinamarca, Jørgen Bo, 1974. Foto: Joana França, 2011.

Figuras 37 e 38 -Primeiro edifício do Programa das Nações Unidas para o Desenvolvimento, PNUD, Lúcio Gomes Machado,Paulo Bruna, José Alfredo Queiroz dos Santos, Pedro Bruna e James Smaul, 2004-12. Fotos: Nelson Kon; Fonte: Paulo Bruna Arquitetos Associados.

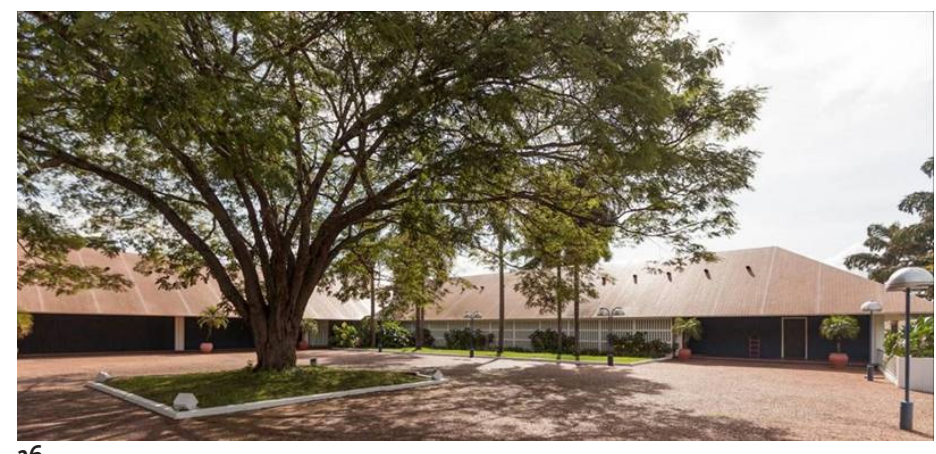

36

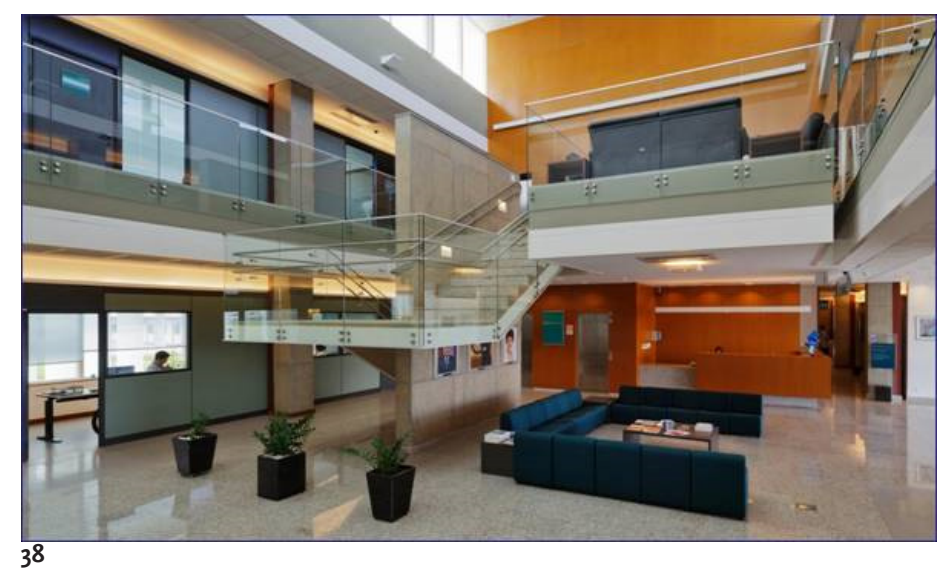

cidade, enquanto outros ainda têm lotes vagos ou estão aguardando a doação de terras. Além daqueles que estão com suas obras em andamento. Este é o caso da sede do Programa das Nações Unidas para o Desenvolvimento, PNUD, projetado por Gomes Machado Arquitetos Associados e Paulo Bruna Arquitetos Associados

em 2004. Em 2011 a proposta foi ampliada, de modo a contemplar a realização do Parque das Nações Unidas, complexo cuja primeira edificação foi concluída em 2012. O que permite fechar esta promenade internacional em uma nota otimista, com uma obra de alta qualidade arquitetônica e excepcional desempenho ambiental.

\section{REFERÊNCIAS BIBLIOGRÁFICAS}

di Matteo, Colette; Tidor, Jean-Martin (org.). Embaixada da França. São Paulo: IOESP, 2009. Ficher, Sylvia; Batista, Geraldo Sá Nogueira. GuiArquitetura Brasília. São Paulo: Empresa das Artes e Editora Abril, 2000.

Mendes, Manuel. O cerrado de casaca. Brasília: Thesaurus, 1995.

Santos, Paulo Roberto Alves dos. Arquitetura estrangeira e outras arquiteturas: embaixadas, delegações e organismos internacionais em Brasília. Brasília: Dissertação de Mestrado, FAU/UnB, 2005.

Sylvia Ficher - Professora Titular da FAU/UnB. Arquiteta (FAU/USP), Mestre em Preservação Histórica (Columbia University, Nova York), Doutora em História Social (FFLCH/USP), com Pós-doutorado em Sociologia (École des Hautes Études en Sciences Sociales, Paris). sficher@unb.br.

Paulo Roberto Alves dos Santos - Arquiteto e Urbanista e Mestre pela Universidade de Brasilia, é professor no Curso de Arquitetura do UniCEUB. paullobetto@gmail.com. 